\title{
Management Problems in Global Crowdsourcing
}

\author{
Zhijiang Liu, Guangxi Normal University, Guilin, China \\ Tatyana Sakulyeva, State University of Management, Moscow, Russia \\ Alexey Mikheev, MGIMO, Moscow, Russia \\ Diana Stepanova, Plekhanov Russian University of Economics, Moscow, Russia
}

\begin{abstract}
The study aimed to develop recommendations for the optimization of settings in which the crowdsourcing project takes place. Findings show that crowdfunding projects are hybrid and include the elements of crowdsourcing, crowdsensing, crowdfunding, crowdworking, and crowdsourced recruitment. The predominant role of security guarantees was identified. It turned out that relations irreducible to a simple hierarchy pose many challenges. The results indicate that leading issues include the lack of financial guarantees and the likelihood of information leakage to competitors. Hence, the priority is to manage the exchange of money and information. An interesting finding demonstrates a positive correlation between project success, ethical conduct, and fair distribution of gains. The protection of intellectual property rights was no less important. As it was concluded in the course of analysis, the more successful the project, the more thoroughly it addresses the protection of someone else's intellectual property.
\end{abstract}

\section{KEYWORDS}

Crowdfunding, Crowdsourcing, Crowdsourcing Project, Social Network, Survey

\section{INTRODUCTION}

The success of crowdsourcing projects goes far beyond managerial and marketing problems; it is a multifaceted process entangling the problems of sociology, psychology, law, etc. Thus, the rational choice hypothesis may not work for infocommunication technologies. The end users can accept the useful crowdsourcing technologies to a variable degree, and this acceptance not always correlates with usefulness (Abdulfattah, 2019). One of the major problems in management is that the slow pace of technology adoption does not meet the burst of technological advancement and innovation (Abdimanapov et al., 2014). Attempts to make use of crowdsourcing as a means for increasing the efficiency are directly related to changes that occur in the information society and knowledge-based economy over time as well as to the advent of novel electronic communications.

Advantages of using crowdsourcing largely depend upon the nature of the task. In general, by implementing crowdsourcing technologies, businesses can (Fuger et al., 2017):

- Save their financial, human, informational, energy and time resources;

DOI: 10.4018/JGIM.20220701.0a3

This article published as an Open Access article distributed under the terms of the Creative Commons Attribution License (http://creativecommons.org/licenses/by/4.0/) which permits unrestricted use, distribution, and production in any medium, provided the author of the original work and original publication source are properly credited. 
- Bring to bear on the knowledge, skills, experience and interests of the crowd and individual participants;

- Bring their outputs to the public;

- Build up contacts with the target audience;

- Encourage others to participate in managerial decision-making;

- Complete projects in a shorter time.

In recent years, crowdsourcing has been developing rapidly around the world, such that small and medium-sized companies raise a significant part of their funds via crowd projects. With the tremendous rise of information technologies such as the Internet of things, cloud computing, etc., different organizations are continuously generating huge amounts of data for various applications. In such circumstances, a management mechanism for handling large-scale data with minimal costs is needed (Sambrekar \& Rajpurohit, 2019).

The global crowdfunding industry grew almost 13-fold in four years, reaching 34.4 billion dollars in 2015 from 27.2 billion dollars in 2012. Hence, the annual increment is over 200 per cent (CF The Crowdfunding Industry Report, 2015). Approaches to data flow management differ among themselves due to the existence of variable data sets. Many authors have developed formalisms for non-uniform data management, e.g., formalisms in "Creating a portable, high-level graph analytics paradigm for compute and data-intensive applications" (Wang et al., 2019).

This study offered a formalism suitable for real-time crowdsourcing management.

According to the 2016-2020 Global Crowdfunding Market Report, the crowdfunding market is projected to grow at the compound annual growth rate (CAGR) of 26.87 per cent during the period 2016-2020 (Global Crowdfunding Market, 2019). According to Technavio's analysts, it is expected to register a CAGR of almost 17 per cent by 2021 (Global Crowdfunding Market 2017-2021, 2019). Among the crowdfunding categories, the most popular include business and entrepreneurship (41.3 per cent), social causes (19 per cent), films and performing arts (12.2 per cent) (CF The Crowdfunding Industry Report, 2015).

The first-category projects are funded via donations, in return for a reward, while social causes and films are financed under schemes where a reward is not implied. In spite of its international nature, 70 per cent of the global crowdsourcing industry is occupied by the US and European platforms. For instance, the top crowdfunding players as of 2018 are North America (1.725.000.000 dollars) and Asia (1.054 billion dollars), followed by Europe (6.480.000.000 dollars) (Global Crowdfunding Market, 2019). In that same year, P2P lending, which is a financing tool that allows individuals to lend money to other individuals, became the most demanded form of crowdfunding, making up twothirds of the market (25 billion dollars). In 2016, the P2P lending segment accounted for almost 70\% of the global market and is projected to decline to $54 \%$ by 2021 , exhibiting almost $16 \%$ decrease in market share (Global Crowdfunding Market, 2019).

This study touched upon difficult-to-define issues such as ethics. Introduced into the framework for the analysis, ethical issues were considered in conjunction with the intellectual property law. The aim was to demonstrate that the respect of project participants to other people's intellectual property and adherence to ethical standards could become a competitive advantage and a key to project success.

Considering the above, the present research is relevant and of interest.

\section{LITERATURE REVIEW}

The term "crowdsourcing" was first mentioned in (Howe, 2006) in 2006. As of now, a considerable amount of empirical material is accumulated, which allows for determining the main crowdsourcing trends. In (Fuger et al., 2017), a general crowdsourcing model was presented. The said model is based on a holistic approach to the adaption of innovations in a company. One of the aspects embraced is the compatibility between different configuration choices of elements within a crowdsourcing 
project. Another work (Hosseini et al., 2015) examined the relationships between all components of the project: the crowd, the crowdsourcer, the task to be solved, and the crowdsourcing platform. In the meanwhile, there is a lack of engineering methods and principles that help create quality crowdsourcing-based solutions.

Today, researchers have not yet reached a consensus on exactly which practices fall within the category of crowdsourcing. In spite of disagreement, several key characteristics have been identified (Wazny, 2017). Among them, crowdsourcing involves the distribution of tasks among a significant number of people (crowd). Although communication between participants traditionally occurs via the Internet, crowdsourcing does not necessarily mean the use of Internet services. Participants in crowdsourcing may receive monetary rewards, recognition, or skill development training. Sometimes, the results become aggregated and the choice is made in favour of the best.

Depending on the context (Simperl, 2015), crowdsourcing:

- provides for the transfer of certain production functions to an indefinite number of persons, and constitutes a public offer, which does not require an employment contract to be signed);

- is mainly used to collect and analyze aggregate data from a crowd;

- refers to the collaboration of people who voluntarily pool resources, mostly financial, usually via the Internet, to support other people or organizations in their efforts;

- helps companies to execute serious tasks by attracting people from all over the world, without making them leave their homes;

- provides means to select the most promising carriers of professional competencies, that is, through observation and evaluation of candidates within the workflow-like context;

- relates to loan-based forms of donation, which involve individuals lending to other individuals or companies using the specially created platform.

Exploring crowdsourcing projects is difficult in terms of methodology. In (Lenart-Gansiniec, 2018), authors draw our attention to that in the theoretical and practical aspects there is still "terminological chaos." In this connection, many aspects cannot be found in the theoretical framework. Many crowdsourcing definitions or interpretations do not contribute to the development of adequate techniques, which can be used to evaluate and compare different crowdsourcing projects. However, those methods that exist also need to be analyzed, and any limitations and inaccuracies that are inherent to them must be abolished.

Various forms of crowdsourcing were considered in (Simperl, 2015), alongside a discussion on their use, which, as claimed, is aimed at turning the conventional content management applications into social machines in which tasks are performed as optimal combinations of human and computational intelligence. There is also a framework introduced for the analysis of the crowdsourcing systems. Factors that promote the development of crowdsourcing include the openness of companies towards ordinary users, the advantage of individuals' creativity in the innovation process, the creation of loyal virtual communities (Zhao, 2019). Kathleen Wilson et al. (2018) were studying the crowdsourcingbased mechanism for increasing the efficiency of project management (Wilson et al., 2018). Considering the experience of five gamification companies in the US and Australia, crowdsourcing offers flexibility, speed, dynamism and scalability to project processes when the operational risks are low.

Taeihagh (2017) explored similarities and differences between different types of crowdsourcing and the sharing economy. The shared features that were established by him involve the use of information technologies, reliance on crowds, monetary exchange, and the use of reputation systems.

Upon that, crowdsourcing campaigns are often launched for social causes (Fuger et al., 2017), those in medicine (Wazny, 2017), promoted by libraries, museums, archives (McKinley, 2012), related to information products (Niu et al., 2019), emergency management (Harrison \& Johnson, 2016), and industrial projects (Saldanha et al., 2014). 
In general, making decisions on crowdsourcing may involve risks, including legal risks that are associated with intellectual property. In this case (de Beer et al., 2017), four different approaches may be applied to crowdsourcing intellectual property: passive, possessive, persuasive, and prudent.

As it is stated in (Iren et al., 2014), the crowdsourcing-based business model it tends to result in lower quality compared with the traditional way of doing work, due to losing worker-employer relationships, skill diversity of the crowd and anonymity of participants. Also, it is crucial to verify characteristics of those involved in the crowdsourcing project and to check the quality of their work at each stage (Naroditskiy et al., 2012; Santos et al., 2014).

Thus, despite the rapid pace of development, international crowdsourcing projects see a low level of responsibility on the part of project initiators and project participants. Additionally, a significant part of payments for the work remains off the book. The purpose of this article is to summarize the experience of participants in the crowdsourcing campaign, donors and initiators, to develop recommendations for the optimization of settings in which the crowdsourcing project takes place.

\section{MATERIALS AND METHODS}

Before developing recommendations for the optimization of settings in which the crowdsourcing project takes place, it is advisable to investigate the experience of participants in such projects first.

With this aim in view, we conducted a survey of 447 respondents using computer-assisted telephone interviewing (CATI). The sampling process was performed in two stages. First, the overall population of Russia was clustered by regions, with the number of random respondents in the cluster group that is proportioned to the total number of residents in the given region. Residents were recruited through random digit dialling. Persons who admitted that they had an experience of participating in the crowdsourcing project were asked if they want to proceed with online testing. Of those who agreed to participate in the survey, $211(47.2 \%)$ previously took part in the crowdsourcing projects. Of these, $183(86.7 \%)$ were acting as participants and donors, while the 28 respondents were project initiators.

Respondents were asked to complete an online survey, the questions of which are shown in Figure 1.

Figure 1. The Graphic View of Online Survey Questionnaire Content (designed by the authors)

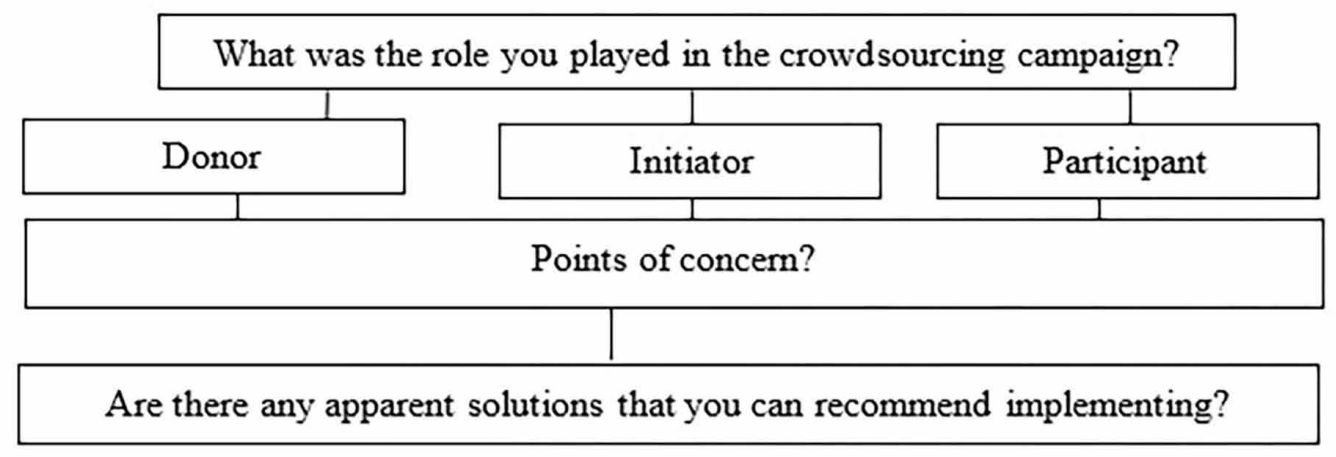

Respondents were given a link to the online survey platform after receiving informed consent to participate in reward-based marketing research. In our opinion, such an approach is reasonable and allows collecting reliable data, since the proportion of Internet users is high enough to extrapolate research results to the entire population. 
To validate data quality, the survey results were compared with the information gathered via profiling and in other projects. Multiple registrations were handled using the built-in platform features and limited to one for a certain time period. The originality of answers was also monitored. The sampling error did not exceed $5 \%$.

The survey results and recommendations developed on their basis are presented below.

\section{RESULTS}

According to the 46th World Economic Forum, the key driver of the upcoming changes in business will be the aligning with digital technologies. The crowdsourcing technology here serves a tool to accomplish this aligning and can be regarded as a contributor to the innovation-driven development (Baeva \& Malyshenko, 2017). In Russia, the crowdsourcing practice is also actively developing, reaching new heights annually.

Table 1, A generalized table, was created on the back of the survey results and provides information about the frequency of answers. Figure 2 puts the table data into a visual.

Table 1. The Crowdsourcing Participation Survey Results

\begin{tabular}{|c|c|c|c|}
\hline Indicator & Donor & Initiator & Participant \\
\hline $\mathrm{N}$ & 74 & 28 & 109 \\
\hline Proportion & $35 \%$ & $13.3 \%$ & $51.6 \%$ \\
\hline \multicolumn{4}{|l|}{ Answer Groups } \\
\hline \multicolumn{4}{|l|}{ Points of Concerns? } \\
\hline Inconsistency in actions & $25(33.8 \%)$ & $11(39.3 \%)$ & $54(49.5 \%)$ \\
\hline Contract non-compliance & $11(14.8 \%)$ & $2(7.1 \%)$ & $87(79.8 \%)$ \\
\hline Project execution changes & $51(68.9 \%)$ & $11(39.3 \%)$ & $91(84.5 \%)$ \\
\hline Financially undisciplined initiators & $37(50 \%)$ & $18(64.3 \%)$ & $48(44 \%)$ \\
\hline Failure to meet deadlines & $67(90.5 \%)$ & $25(89.3 \%)$ & $94(86.3 \%)$ \\
\hline Low quality output & $58(78.4 \%)$ & $22(78.6 \%)$ & $54(49.5 \%)$ \\
\hline Self-indulgent participants & $52(70.3 \%)$ & $20(71.4 \%)$ & $93(85.3 \%)$ \\
\hline Participant overextending themselves & $73(98.6 \%)$ & $28(100 \%)$ & $100(91.7 \%)$ \\
\hline Lack of professional involvement & $65(87.8 \%)$ & $2(7.14 \%)$ & $94(86.2 \%)$ \\
\hline Poor project planning & $63(85.1 \%)$ & $21(75 \%)$ & $87(79.8 \%)$ \\
\hline Financial fraud & $38(51.3 \%)$ & $7(25 \%)$ & $84(77 \%)$ \\
\hline \multicolumn{4}{|c|}{ Are There Any Apparent Solutions That You Can Recommend Implementing? } \\
\hline Project feasibility study & $24(32,4 \%)$ & $11(39.3 \%)$ & $102(93.6 \%)$ \\
\hline $\begin{array}{l}\text { Displaying information about project participants } \\
\text { and initiators }\end{array}$ & $23(31 \%)$ & $27(96.4 \%)$ & $95(87.2 \%)$ \\
\hline
\end{tabular}

According to the survey data, there are two large groups of recommendations, which boil down to the following (Figure 3): 
Journal of Global Information Management

Volume 30 • Issue 3

Figure 2. The Frequency of Responses in the Survey

120

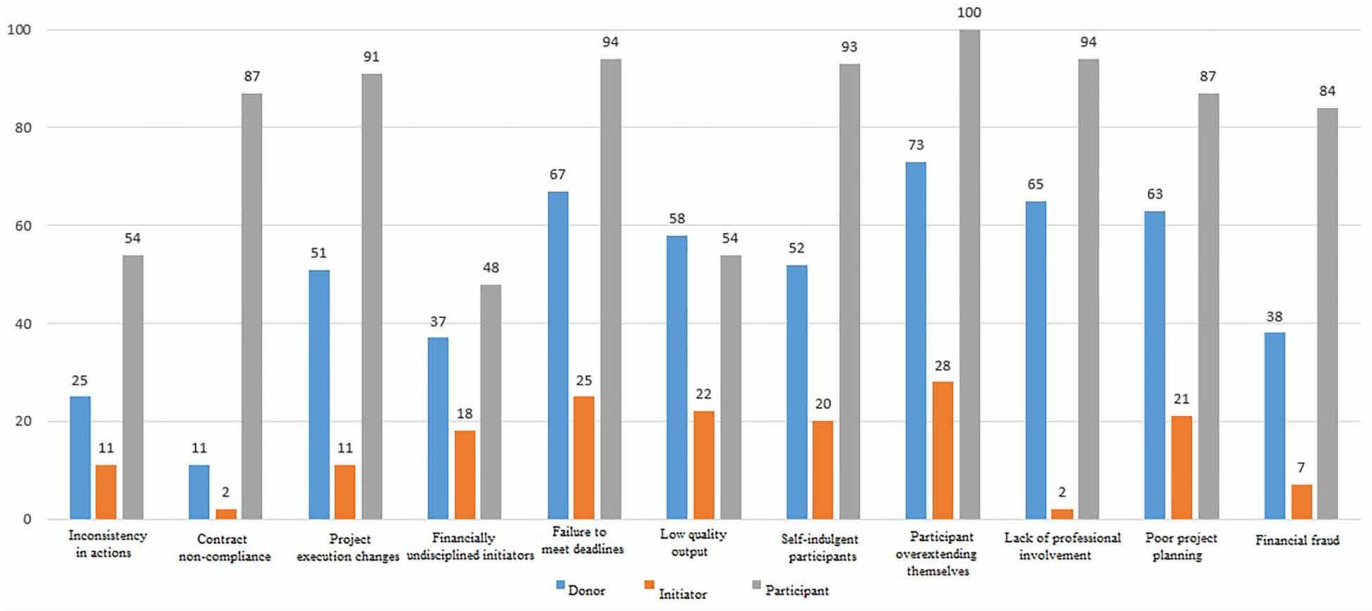

Figure 3. The Frequency of Recommendations

120

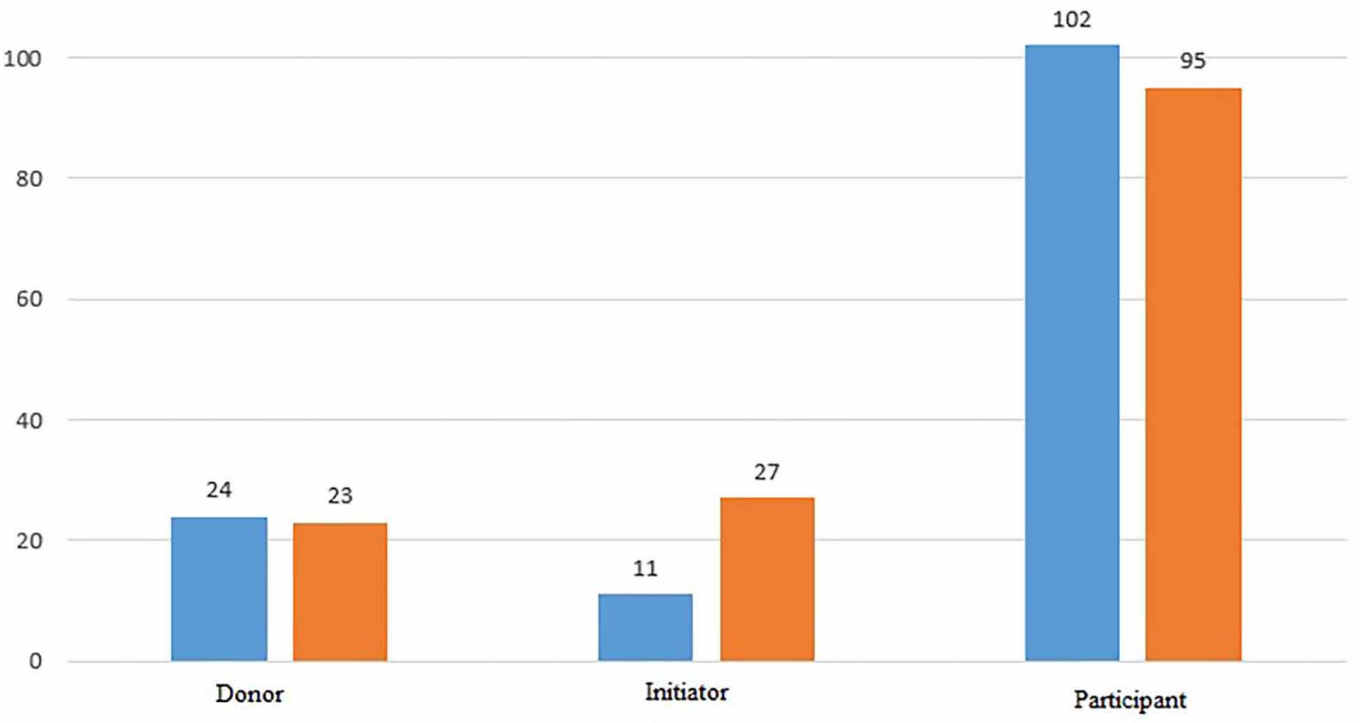

- Attracting professionals for project evaluation

a Portraying project initiators and participants 
- Companies must carefully weigh the decisions they make on the projects and launch only wellelaborated projects, those that were evaluated by a professional and those having a good business plan;

- Crowdsourcing platforms must deanonymize the participants, especially in projects that offer financial rewards.

The current crowdfunding projects are usually hybrid and include the elements of crowdsourcing, crowdsensing, crowdfunding, crowd working, and crowdsourced recruitment (Figure 4).

Figure 4. The Crowdsourcing Process Flow Chart

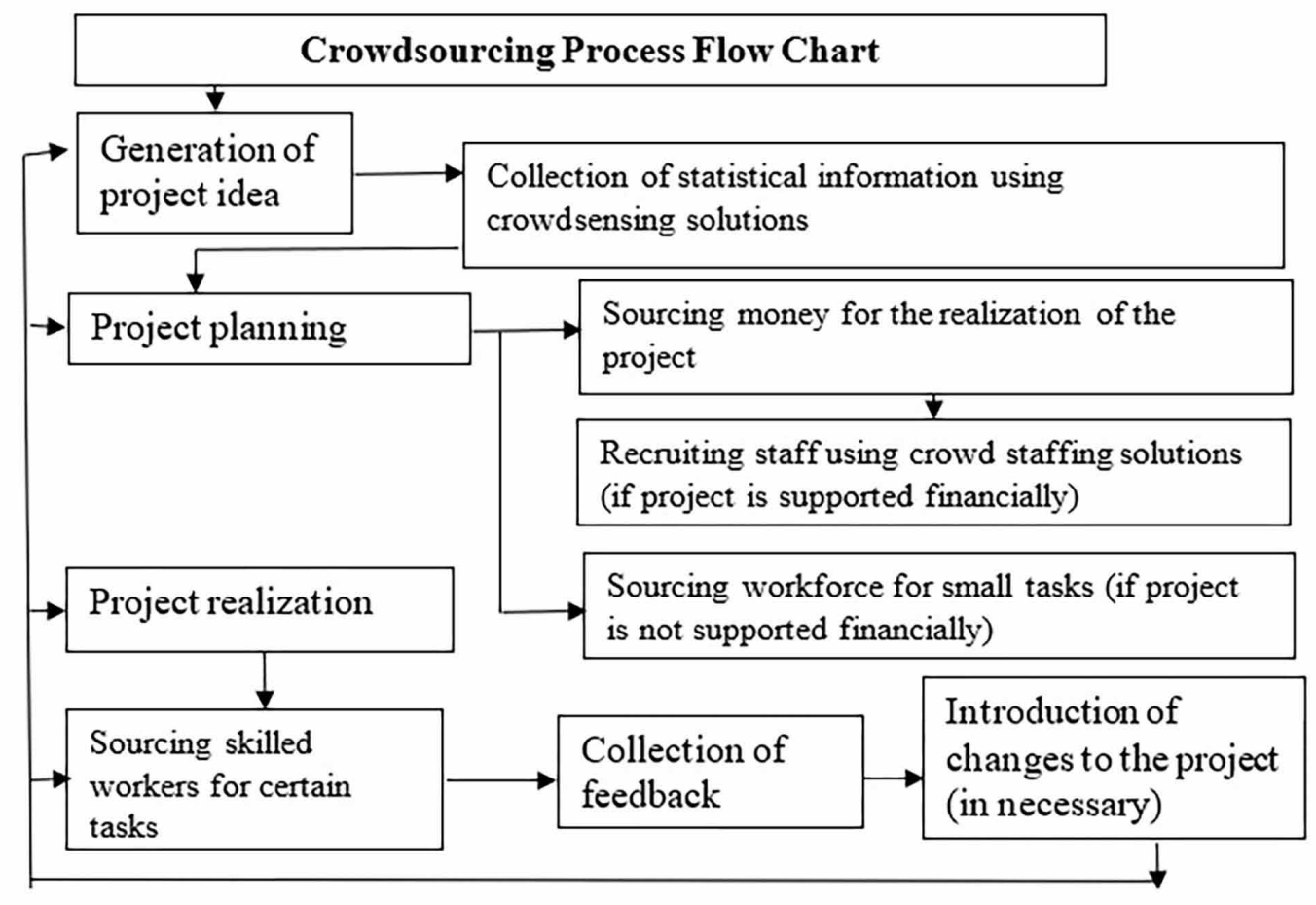

Due to the lack of contractual relationship between participants in the project and its initiators, the major problem that arises in crowdsourcing is the lack of financial guarantees. Additionally, participants may be involved in the leaking of project-related information to competitors at any stage of project realization, which places a question mark over the reasonability of crowd involvement. These problems can emerge alongside secondary issues:

- valuable information leakage due to the actions of malicious executants;

- project abandonment;

- the lack of discipline among participants, especially after receiving an advance payment;

- the lack of mechanisms for influencing project participants;

- self-indulgent and unpredictable behaviour of participants. 
The act of deanonymizing participants and initiators by referring to their social pages will provide parties that are involved in the crowdsourcing project with the following information about the workforce standing behind the project:

1. Competencies and skills, from professional to specific such as:

1) teamwork competence;

2) soft skills;

3) creativity

4) systematic thinking, etc.;

2. Details about the personality:

1) tolerance to constructive criticism;

2) character traits (attentiveness, perseverance, diligence, being trustworthy);

3. Project participation/realization statistics.

From this perspective, managing money and information flows (Figures 5 and 6 ) is the priority to ensure the overall, financial and information security within the project.

Figure 5. The Information Exchange Cycle in Crowdsourcing

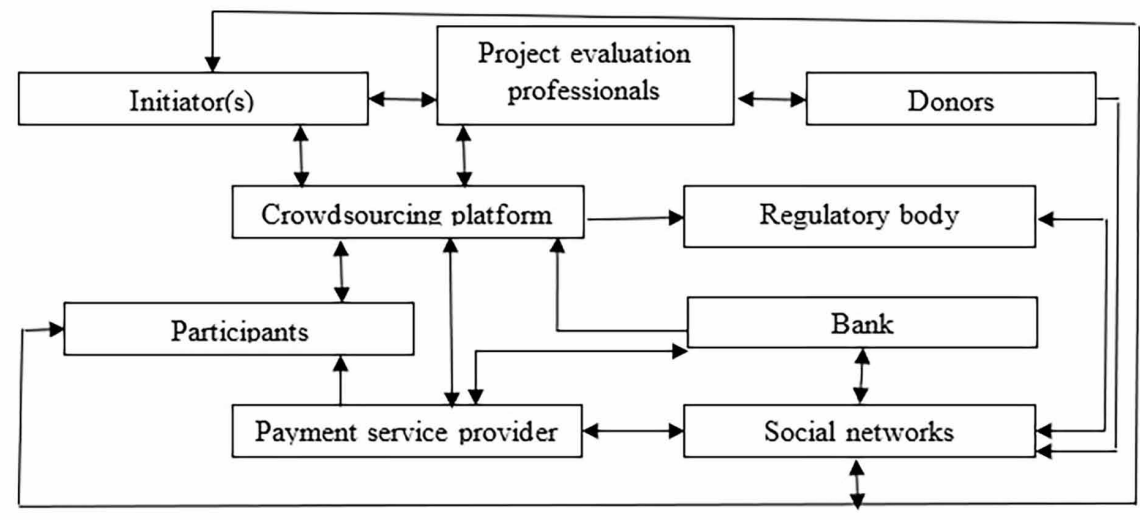

Figure 6. The Journey of Payments made within the Crowdsourcing Project Framework

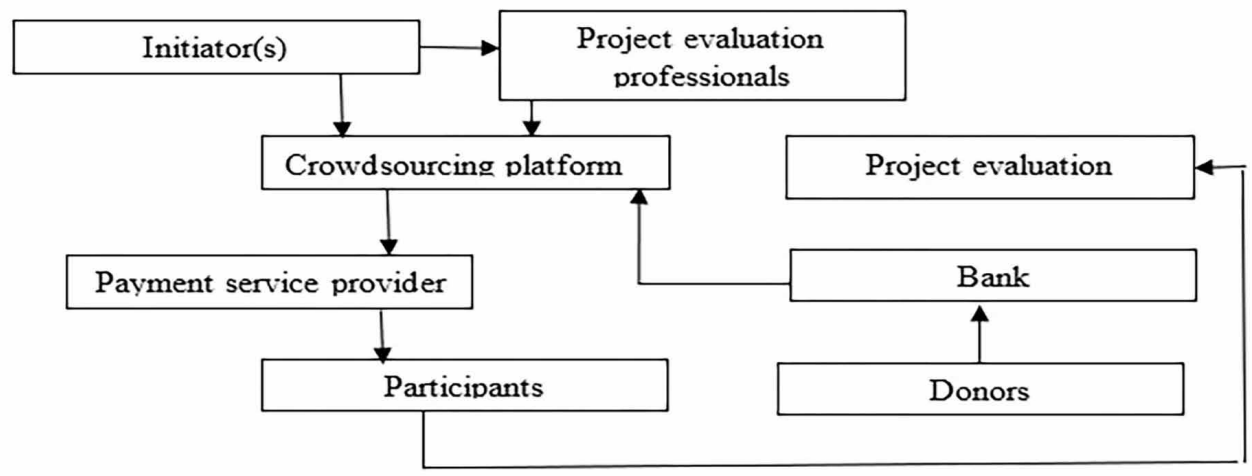


To successfully promote crowdsourcing, initiators must increase their communication with the crowd. For this purpose, mediators such as crowdsourcing agencies and platforms that combine functions of an information website and a financial intermediary may be involved. The most famous crowdsourcing platforms are the AmazonMechanical Turk (MTurk) and the InnoCentive. There are also cases of capital rise via highly specialized intermediaries (e.g., using blog posts). In this case, initiator turns to the crowd with a specific problem (e.g., posts a message will all the insights needed), sets a timeframe and a certain reward for its solution. The initiator has no right to directly influence the crowdsourcing process.

The crowdfunding process differs from crowdsourcing in terms of mediators. The crowdfunding platforms provide for the accumulation of financial resources. The Kickstarter, for example, is a platform where project initiators can set the funding goal, the timeframe, and a reward for each specific project.

In crowdsourcing, participants in communication are engaged in the equality-based work relationship; hence, exploitation and propaganda are not an issue here, especially if there is an opportunity to make public the cases of non-payments, fraud, failure to meet deadlines, etc. Thus, removing confidentiality of information about participants in the crowdsourcing project and its initiators by referring their social webpages ensures both the information security and financial discipline. This approach is aimed at protecting the participants. Yet, services that help employees influence the level of wages and work arrangements are increasingly emerging.

In the context of virtual communication and weak formal institutions, the role of social ties is gaining importance, such that these ties become the main leverage to increase work efficiency and protect against precarization. The long-term cooperation relationships and contacts that were built up through the social networks result in trust between parties and guarantee the fulfilment of obligations.

Social networks are not subject to crisis and external factors, they do not depend on the political, economic, environmental, or demographic situation in a country or region. The only threat here is a decrease in attendance; however, there is always an opportunity to change the platform.

Social networks provide a detailed statistic about the use of links, articles, and content distribution. Moreover, they can be used to popularize crowdsourcing projects and attract investors.

The crowdfunding platforms can set a pledge threshold so that the funds are transferred only upon meeting it but not every platform has such a feature. The use of a pledge crowdfunding mechanism depends on the choice of a business model.

We suggest considering the following indicators of the crowdsourcing campaign:

1. Goal Fulfillment Rate. Reflects the quality of project promotion;

2. Average Donation.

3. The Number of Donors.

4. The Number of Page Views.

5. The Number of Clicks that Project Received. Reflects the success of a PR campaign;

6. The Proportion of New Investors. Reflects the success of project promotion;

7. Investor-to-Total Viewers Ratio. Allows the project initiator to evaluate the return on the innovation idea;

8. The Number of Comments Left. Projects may be of different interest to platform users.

9. Statistics collected for other projects that were launched by the same initiator(s);

10. Project Openness (this refers to the provision of information about fundraising progress and professional views).

Project initiators can understand the opinion of potential buyers about the project idea by analyzing the tone in which they write. It is also crucial to respond to almost every comment, which they leave.

Crowdsourcing solutions are gaining popularity among small investors who seek a platform for the accumulation of small capital in return for a certain reward. Such investors will not become business 
angels, as they do not have sufficient resources for independent or share financing of innovations. Beyond that, the popularity of this method is pumped by a decrease in the public confidence in banks, which was triggered after some of them reached bankruptcy.

\section{DISCUSSION}

The crowdsourcing event is an ambiguous phenomenon. It can take place as part of economic (i.e., via investing activity as well as in business and financial management), socio-psychological (i.e., as a group and consumer behaviour of participants) and marketing (i.e., for product promotion, collection and analysis of feedback, advertising, and PR campaign) processes.

With the advancement of web technologies, many people are participating in the information production and distribution process in the Web environment. Because the amount and complexity of web information is rapidly increasing, many researchers are interested in refining useful information through a topic-based recommendation system (Kim et al., 2018). The collective creativity processes were no exception. Crowdsourcing as a practice of collective creativity existed earlier but only in the last decade, crowdsourcing began to rely mainly on network communications, which gives rise to many opportunities and radically expands the circle of actors. With the proliferation of smart devices and the growth of network technology, anyone can easily access web data. In addition, everyone can take an active part in the information production and distribution processes and thus promote a rapid increase in the amount and complexity of web data. Big data refers to structured or unstructured data that cannot be collected or analyzed using traditional methods, i.e., the working traffic within the crowdsourcing community (Kim et al., 2018).

The research method that was used in this study - investigation on completed projects - is often used by other scholars and can be an example of good practice. For instance, the work (Godin \& Terekhova, 2019) rose an important problem of personalizing the experience and contribution of each crowdsourcing project participant. Personalization can be interpreted as an indispensable component of recognition and thus be linked to the ethical side of the project, which distinguishes a relatively new crowdsourcing approach from the traditional corporate practices in which personalization is only seen as a necessary evil.

Challenges of management in crowdsourcing drew attention of many authors. The work (Das Sarma et al., 2016) investigated worker responses to control actions, rose an important problem of management optimization, and showed all the harmfulness of limiting to local goals.

Crowdsourcing is no longer exclusively a private initiative. Not only state-owned companies but even different-level governments in the US are starting to use or plan to use crowdsourcing as a tool to implement policies/programs, engage the public, gather information or improve services in any way. Projects vary in size, outcome, degree of collaboration, and often in effectiveness. However, a technically competent community is increasingly involved in government projects (Clark et al., 2019). However, the work (Ettlinger, 2016) puts forward a crucial consequence of employing crowdsourcing practices in public administration. The danger of infringing the rights of employees and increased concern about their exploitation were emphasized. In contrast to the corporate discipline of previous management approaches, the new ones that are based on crowdsourcing practices need to place ethical issues in the forefront. To resolve these issues, organizations must optimize their work within the framework of crowdsourcing projects. "Ethics is a new oil," one could say in an aphoristic fashion.

However, most of the existing solutions for assessing employee responses to managerial influences in crowdsourcing projects face serious challenges. Due to negligence of the ethical component in the previous corporate practices, some of them can bring only locally optimal results with low accuracy, while other strategies pay a high price to achieve overall optimality. A crowdsourcing project is a specific tool that needs additional study to adapt managerial practices (Zhang et al., 2018). In addition to the ethical side of a crowdsourcing project, some authors drew their attention to the project configuration as a key success factor. Such opinions are fair, however, links that exist between 
dependencies and relationships in a crowdsourcing project are intriguing and can be developed from the ethical perspective (Hosseini et al., 2019). Another interesting work (Callaghan, 2016) is based on the theory of knowledge management. Authors argue that the problem of knowledge aggregation is a fundamental limitation for creating knowledge and innovation in crowdsourcing projects. Specific reasons for the failure of innovations include the inability of $R \& D$ to distinguish between intellectual property that was produced and borrowed when implementing a crowdsourcing project. This approach may be considered management and akin to that addressed here. Note that specific consequences of innovation failure are expressed as the inability of R\&D to deliver new medication or the inability of profit-oriented innovative models to absorb positive external effects, which are associated with innovation (Callaghan, 2016). Additionally, problems with innovation can lead to the failure of academic research or the inability to provide much-needed social innovations. Hence, an evident problem needs a positive counterexample, such as one tackled in ( $\mathrm{Li}$ et al., 2018) and in (Li et al., 2017). These two papers serve successful solutions to the crowdsourcing project contradictions.

At the current stage of economic development, crowdsourcing is considered the leverage of a large group of people to do the work that was previously conducted by one specialist alone. The concept in question refers to the compliance with the open-source principles in areas that not related to programming. The crowdsourcing campaign is viewed as a means of problem-solving, which turns to numerous organizations for assistance, most often via the Internet. It is a business model within the framework of which a company outsources tasks to a third party or a group of consumers (i.e., a crowd). Making use of the Internet allows organizing the interaction between consumers in a simple way and without unnecessary expenses as well as approach tasks that were unimaginable in the era before the Internet. Crowdsourcing can strengthen the provider-consumer relationships. Using the advantages of a crowdsourcing platform, consumers can receive the desired services, ideas and any other content from the crowd, usually the online communities, rather than regular employees or suppliers. People who are acting independently are ready to provide their services in return for experience, recognition or reward. Modern-day employers understand that technological advances allow people to develop their skills and talents without leaving home, so they use social media and online forums where people are invited to participate in the projects. Nevertheless, this poses various security challenges and challenges associated with the transfer of large data volumes (Gou et al., 2017).

Crowdsourcing is part of what an American economist and innovation specialist Eric Von Hippel calls the user-centred innovation. In his own words, "Innovation is rapidly becoming democratized. Users, aided by improvements in computer and communications technology, increasingly can develop their new products and services. These innovating users-both individuals and firms-often freely share their innovations with others, creating user-innovation communities and a rich intellectual commons (Von Hippel, 2009)."

Thus, crowdsourcing has changed. Now, it is a modern management tool, which allows solving business problems by utilizing the knowledge potential of employees, customers, and partners.

The crowdsourcing platforms are to a greater extent one of the effective communication tools implemented within the framework of an innovative project, rather than a direct source of funding. If properly conducted, the crowdfunding campaign draws attention to the idea thereby increasing the chances of an innovative project to win the attention of consumers and investors. With this approach to crowdsourcing, it is the attracted audience feedback that is the indicator of success, rather than funds raised.

The potential of socially active collective mind is that it provides for the encouragement and engagement of Internet users to solve a clearly stated problem. In doing so, the collective mind finds new opportunities for building up multidimensional contacts with society.

The concept of crowdsourcing has been criticized though, due to application- and managementrelated cons. The number one claim of crowdsourcing opponents is that the crowd is anything but smart; it is not able to create valuable things, as it consists of different people who will fail to agree upon and develop an effective solution. Most often, a solution rises when the crowd itself consistently 
rejects incorrect decisions and thereby settles on a positive result. The second disadvantage is an unfair reward. Only a limited number of people receive a reward, while the remaining participants work for free. This gives rise to a belief that professionals make little account of crowdsourcing technologies since they value their own time and do not want to waste it. However, almost all platforms for creative crowdsourcing (approach in which participants create complex labour-intensive products) suggest working based on prototypes or limited solutions. Further work, in this case, is possible only when the customer defines one or several winners. For many professionals in developing countries, taking part in crowdsourcing projects may be a major source of income.

Third, the crowdsourcing solution is not necessarily the cheapest way of solving a problem. For example, hiring a logo designer to create a trademark is often a money-saving decision because resources allocation for logo showcase, communication with the audience, and advertising need additional funds to be put into action. The last two disadvantages are information leakage and inconsistency in the actions of participants.

According to our observations, the major problems with the crowdsourcing campaigns are that the initiated projects are not elaborated to a sufficient extent and lack the levers of influence on participants in the project (to make them deliver on obligations) and on the initiators (to make them pay for the work). The increase in data volume managed by an information manager over the past decades has affected the need to protect some confidential pieces of information. An extensive review of new challenges facing the cyber security industry is given in (Gupta, 2018). To ensure a safe cyberspace, recent authors give a list of diverse methods. In (Jiang et al., 2018), authors suggest using deep neural networks. Although neural networks are commonly utilized as a computing tool, we can witness, perhaps for the first time, a case where neural networks were applied for transaction security purposes. The emergence of such an exotic tool may serve an indirect marker of both the complexity of problems in question and unsatisfactory security of network protocols. A similar exotic tool to analyze crowd interactions was shown in (Ramos et al., 2018). Their approach may be promising and developed around issues described here. Metaheuristic algorithms serve as an example of adequate solutions to difficult problems, such as the security of participants in a crowdsourcing project.

To increase the crowdsourced security and the likelihood of crowdsourcing project implementation, platforms must deanonymize both the participants and the initiators of the crowdsourcing project. Consequently, social networks will play a key role in the development of crowdsourcing, which was the reason for its emergence in the first place. In social communities, individuals exchange information constantly and in doing so they create an opportunity for generating, distributing and discussing benevolent content. Through the rapid dissemination of information, social networks have the ability to mobilize human resources within a short timeframe to solve any social problem as well as provide the history of activity of individual participants and initiators.

That way, various websites and social networks, which are used to popularize the crowdsourcing projects and attract investors, resemble a unique phenomenon, as they transform the accumulated social capital into financial capital. The crowdsourcing platforms can also be used to implement research projects and undertakings. A crowdsourcing project is characterized by a broad range of subjects, microfinancing, cross-border engagement of participants, networked organization, and by cost-effectiveness (Simperl, 2015).

\section{CONCLUSION}

The current crowdfunding projects are usually hybrid and include the elements of crowdsourcing, crowdsensing, crowdfunding, crowdworking, and crowdsourced recruitment

Today, researchers have not yet reached a consensus on exactly which practices fall within the category of crowdsourcing. According to different sources, the act of crowdsourcing involves the distribution of tasks among a significant number of people. Although communication between participants traditionally occurs via the Internet, crowdsourcing does not necessarily mean the use 
of Internet services. Participants in crowdsourcing may receive monetary rewards, recognition, or skill development training. Sometimes, the results become aggregated and the choice is made in favour of the best.

Due to the lack of contractual relationship between participants in the project and its initiators, the major problem that arises in crowdsourcing is the lack of financial guarantees. Additionally, participants may be involved in the leaking of project-related information to competitors at any stage of project realization, which places a question mark over the reasonability of crowd involvement. These problems can emerge alongside the secondary issues such as the leaking of valuable information due to the actions of malicious executants; project abandonment; the lack of financial discipline; the lack of mechanisms for influencing project participants; self-indulgent and unpredictable behaviour of participants.

Respondents in this study recommend companies to carefully weigh their decisions regarding the projects and to launch only well-elaborated projects. Aside from that, the crowdsourcing platforms must deanonymize the participants, especially in projects that offer financial rewards. Such an approach allows the increase in responsibility for the quality of work and financial matters.

\section{ACKNOWLEDGMENT}

Zhijiang Liu was supported by Guangxi Natural Science Foundation (2022): The Influence of Innovation Failure Experience on Innovation Behavior: from the perspective of Resilience;Key project of Guangxi Social Science Think Tank (2021): Analysis and Research on Key Success Factors of Guangxi Private Enterprises Digital Transformation. 


\section{REFERENCES}

Abdimanapov, B., Sabdenalieva, G., Muzdybayeva, K., Tastanova, B., \& Kaimuldinova, K. (2014). Conceptual Framework for Ensuring Security of the Territory and the Management of Natural Risks. World Applied Sciences Journal, 30(5), 592-596. doi:10.5829/idosi.wasj.2014.30.05.14057

Abdulfattah, F. H. (2019). Factors Affecting Students' Intention Toward Mobile Cloud Computing: Mobile Cloud Computing. International Journal of Cloud Applications and Computing, 9(2), 28-42. doi:10.4018/IJCAC.2019040102

Baeva, O. N., \& Malyshenko, G. V. (2017). On issue of essence and scales of using crowdsourcing. Baikal Research Journal, 8(2). (in Russian)

Callaghan, C. W. (2016). A new paradigm of knowledge management: Crowdsourcing as emergent research and development. Southern African Business Review, 20(1), 1-28. doi:10.25159/1998-8125/6041

CF The Crowdfunding Industry Report. (2015). Retrieved from http://reports.crowdsourcing.org/index.php?route=product/ product\&product_id=54

Clark, B. Y., Zingale, N., Logan, J., \& Brudney, J. (2019). A framework for using crowdsourcing in government. In Social Entrepreneurship: Concepts, Methodologies, Tools, and Applications (pp. 405-425). IGI Global.

Das Sarma, A., Parameswaran, A., \& Widom, J. (2016, June). Towards globally optimal crowdsourcing quality management: The uniform worker setting. In Proceedings of the 2016 International Conference on Management of Data (pp. 47-62). doi:10.1145/2882903.2882953

de Beer, J., McCarthy, I. P., Soliman, A., \& Treen, E. (2017). Click here to agree: Managing intellectual property when crowdsourcing solutions. Business Horizons, 60(2), 207-217. doi:10.1016/j.bushor.2016.11.002

Ettlinger, N. (2016). The governance of crowdsourcing: Rationalities of the new exploitation. Environment and Planning A. Economy and Space, 48(11), 2162-2180.

Fuger, S., Schimpf, R., Füller, J., \& Hutter, K. (2017). User roles and team structures in a crowdsourcing community for international development-a social network perspective. Information Technology for Development, 23(3), 438-462. do i:10.1080/02681102.2017.1353947

Global Crowdfunding Market 2016-2020. (2019). Retrieved from https://www.marketresearchstore.com/report/globalcrowdfunding-market-2016-2020-45637

Global Crowdfunding Market 2017-2021. (2019). Retrieved from https://finance.yahoo.com/news/global-crowdfundingmarket-2017-2021-182400851.html

Godin, V. V., \& Terekhova, A. E. (2019). Digital advertising as a tool to promote goods or services. Project implementation experience. Event Management, 2(3), 13-21.

Gou, Z., Yamaguchi, S., \& Gupta, B. B. (2017). Analysis of various security issues and challenges in cloud computing environment: a survey. In Identity Theft: Breakthroughs in Research and Practice (pp. 221-247). IGI Global. doi:10.4018/978-1-5225-0808-3.ch011

Gupta, B. B.(Ed.). (2018). Computer and cyber security: principles, algorithm, applications, and perspectives. CRC Press.

Harrison, S. E., \& Johnson, P. A. (2016). Crowdsourcing the disaster management cycle. International Journal of Information Systems for Crisis Response and Management, 8(4), 17-40. doi:10.4018/IJISCRAM.2016100102

Hosseini, M., Phalp, K., Taylor, J., \& Ali, R. (2015). On the Configuration of Crowdsourcing Projects. International Journal of Information System Modeling and Design, 6(3), 27-45. doi:10.4018/IJISMD.2015070102

Hosseini, M., Phalp, K., Taylor, J., \& Ali, R. (2019). On the configuration of crowdsourcing projects. In Crowdsourcing: Concepts, Methodologies, Tools, and Applications (pp. 33-52). IGI Global.

Howe, J. (2006). The rise of crowdsourcing. Wired Magazine, 14(6), 1-4.

Iren, D., \& Bilgen, S. (2014). Cost of quality in crowdsourcing. Human Computation (Fairfax, Va.), 1(2), $283-314$. doi:10.15346/hc.v1i2.14 
Jiang, F., Fu, Y., Gupta, B. B., Lou, F., Rho, S., Meng, F., \& Tian, Z. (2018). Deep learning based multi-channel intelligent attack detection for data security. IEEE Transactions on Sustainable Computing.

Kim, M., Gupta, B. B., \& Rho, S. (2018). Crowdsourcing based scientific issue tracking with topic analysis. Applied Soft Computing, 66, 506-511. doi:10.1016/j.asoc.2017.09.028

Lenart-Gansiniec, R. (2018). Methodological challenges of research on crowdsourcing. Journal of Entrepreneurship. Management and Innovation, 14(4), 107-126.

Li, Z., Nie, F., Chang, X., \& Yang, Y. (2017). Beyond trace ratio: Weighted harmonic mean of trace ratios for multiclass discriminant analysis. IEEE Transactions on Knowledge and Data Engineering, 29(10), 2100-2110. doi:10.1109/ TKDE.2017.2728531

Li, Z., Nie, F., Chang, X., Yang, Y., Zhang, C., \& Sebe, N. (2018). Dynamic affinity graph construction for spectral clustering using multiple features. IEEE Transactions on Neural Networks and Learning Systems, 29(12), 6323-6332. doi:10.1109/TNNLS.2018.2829867 PMID:29994548

McKinley, D. (2012). Practical management strategies for crowdsourcing in libraries, archives and museums. Retrieved from http://www.digitalglam.org/crowdsourcing/crowdsourcing-strategies/

Naroditskiy, V., Rahwan, I., Cebrian, M., \& Jennings, N. R. (2012). Verification in referral-based crowdsourcing. PLoS One, 7(10), e45924. doi:10.1371/journal.pone.0045924 PMID:23071530

Niu, X. J., Qin, S. F., Vines, J., Wong, R., \& Lu, H. (2019). Key crowdsourcing technologies for product design and development. International Journal of Automation and Computing, 16(1), 1-15. doi:10.1007/s11633-018-1138-7

Ramos, J., Nedjah, N., de Macedo Mourelle, L., \& Gupta, B. B. (2018). Visual data mining for crowd anomaly detection using artificial bacteria colony. Multimedia Tools and Applications, 77(14), 17755-17777. doi:10.1007/s11042-017-5382-6

Saldanha, F. P., Cohendet, P., \& Pozzebon, M. (2014). Challenging the stage-gate model in crowdsourcing: The case of Fiat Mio in Brazil. Technology Innovation Management Review, 4(9), 28-35. doi:10.22215/timreview/829

Sambrekar, K., \& Rajpurohit, V. S. (2019). Fast and Efficient Multiview Access Control Mechanism for Cloud Based Agriculture Storage Management System. International Journal of Cloud Applications and Computing, 9(1), 33-49. doi:10.4018/JJCAC.2019010103

Santos, C. P., Khan, V. J., \& Markopoulos, P. (2014, November). On utilizing player models to predict behavior in crowdsourcing tasks. In International Conference on Social Informatics (pp. 448-451). Springer.

Simperl, E. (2015). How to use crowdsourcing effectively: Guidelines and examples. LIBER Quarterly, 25(1), 18-39. doi:10.18352/lq.9948

Taeihagh, A. (2017). Crowdsourcing, sharing economies and development. Journal of Developing Societies, 33(2), 191-222. doi:10.1177/0169796X17710072

Von Hippel, E. (2009). Democratizing innovation: The evolving phenomenon of user innovation. International Journal of Innovation Science, 1(1), 29-40. doi:10.1260/175722209787951224

Wang, H., Han, H., Wang, X., Fang, R., \& Mei, W. (2019). A high efficient map-matching algorithm for the GPS data processing intended for the highways. International Journal of High Performance Computing and Networking, 13(2), 132-140. doi:10.1504/IJHPCN.2019.097504

Wazny, K. (2017). "Crowdsourcing” ten years in: A review. Journal of Global Health, 7(2), 020601. doi:10.7189/ jogh.07.020601 PMID:29302322

Wilson, K. B., Bhakoo, V., \& Samson, D. (2018). Crowdsourcing: A contemporary form of project management with linkages to open innovation and novel operations. International Journal of Operations \& Production Management, 38(6), 1467-1494. doi:10.1108/IJOPM-12-2016-0753

Zhang, Y., Cui, L., Huang, J., \& Miao, C. (2018, July). CrowdMerge: Achieving Optimal Crowdsourcing Quality Management by Sequent Merger. In Proceedings of the 3rd International Conference on Crowd Science and Engineering (pp. 1-8). doi:10.1145/3265689.3265714

Zhao, Z. (2019). Idea Crowdsourcing for Innovation: Fundamentals and Recommendations. Management \& Data Science, 3(2). 